\title{
ERRATUM
}

Hanna Wilczura-Wachnik · Svava Ósk Jónsdóttir

\section{Modeling of the phase equilibria of polystyrene in methylcyclohexane with semi-empirical quantum mechanical methods I}

\section{J Mol Model (2003) 9:108-113}

Due to a mistake in the numerical calculations the graph shown on Figure 4 is incorrect. The correct graph is given below. This does not affect the main results and conclusions of this paper.
The online version of the original article can be found at http:// dx.doi.org/10.1007/s00894-003-0119-z

H. Wilczura-Wachnik $(\bowtie)$

The Faculty of Chemistry, Warsaw University,

Pasteura 1 Street, 02-093 Warsaw, Poland

E-mail: wilczura@alfa.chem.uw.edu.pl

Tel.: + 482282200211

S. Ó. Jónsdóttir

Department of Chemistry,

Technical University of Denmark,

2800 Lyngby, Denmark

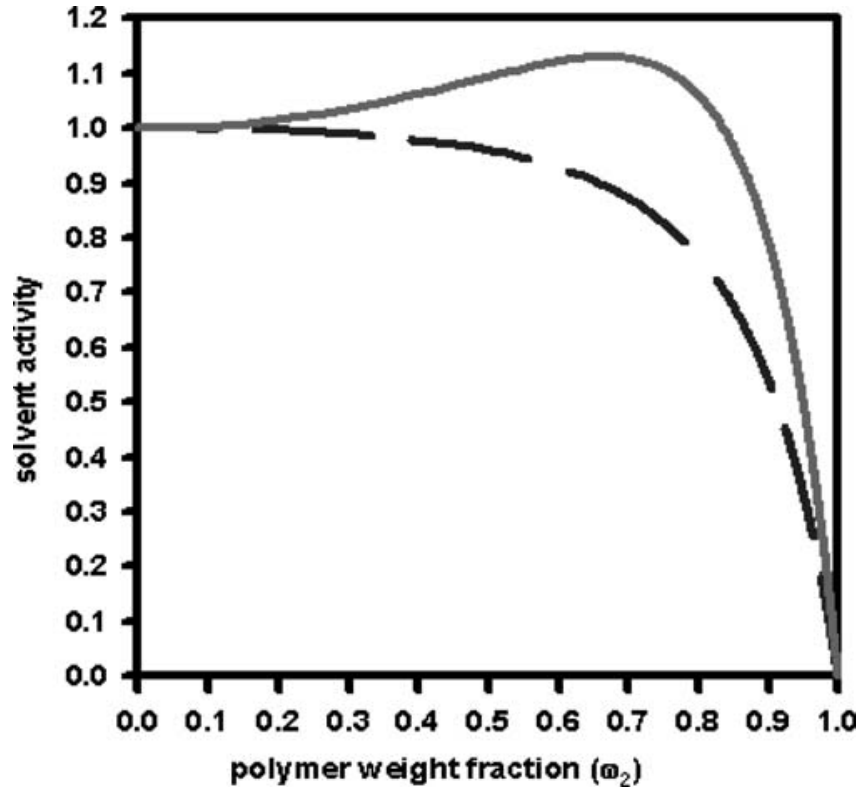

Fig. 4 Solvent acticities for the methylcylcohexane(1) + polystyrene(2) system at $316 \mathrm{~K}$. parameters $a_{i j}$ obtained with the AM1 method; _ parameters $a_{i j}$ from VLE data for the ethylbenzene + methylcyclohexane system [28]. The abscissa is the polymer weight fraction defined as $\omega_{2}\left(x_{1}\right)=\left(1-x_{1}\right) M_{2}$ $\left[x_{1} M_{1}+\left(1-x_{1}\right) M_{2}\right]$ where $x_{1}$ is the solvent mole fraction and $M_{\mathrm{i}}$ are the molecular weights of the components 